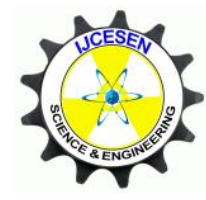

Copyright (C) IJCESEN
International Journal of Computational and

Experimental $\boldsymbol{S}$ cience and Engineering

(IJCESEN)

Vol. 3-No.1 (2017) pp. 29-32

http://iakkurt.dergipark.gov.tr/ijcesen

Research Article

\title{
Design of low power DTMOS based FCS and its notch filter application for ECG signals ${ }^{\#}$
}

\author{
Hatice Gül UGRANLI ${ }^{1}$, Melih YILDIRIM ${ }^{2}$ and Fırat KAÇAR ${ }^{3}$ \\ ${ }^{1}$ Bartin University, Faculty of Engineering, Department of Electrical-Electronics Engineering, Bartin, TURKEY. \\ ${ }^{2}$ Bitlis Eren University, Faculty of Engineering and Architecture, Department of Electrical-Electronics Engineering, \\ Bitlis, TURKEY. \\ ${ }^{3}$ Istanbul University, Faculty of Engineering, Department of Electrical-Electronics Engineering, Istanbul, TURKEY. \\ * Corresponding Author : hgulsezgin@bartin.edu.tr \\ (First received 25 November 2016 and in final form 20 February 2017) \\ \# Presented in " $3^{\text {rd }}$ International Conference on Computational and Experimental Science and Engineering (ICCESEN-2016)" \\ Keywords \\ Floating Current Source \\ Dynamic Threshold Voltage \\ MOSFET \\ Notch Filter \\ Powerline Interference \\ Electrocardiograph

\begin{abstract}
In this study, p-MOSFETs in floating current source circuit are converted to dynamic threshold voltage MOSFET structure and a second order notch filter application is carried out by using the DTMOS based FCS circuit. The proposed model is simulated in LTSPICE simulator by using Taiwan Semiconductor Manufacturing Company $0,18 \mu \mathrm{m}$ CMOS technology. DTMOS structure allows the operation of the circuit at lower power about 4,95nW. Operating frequency of notch filter consisting of the DTMOS-FCS circuit is set up to suppress the undesirable effects of power-line interference on the electrocardiograph signals.
\end{abstract}

\section{Introduction}

Electrocardiograph (ECG) signals are exposed to distortion by several noise sources such as electric power system and recording electrodes $[1,2]$. And power-line interference (PLI) (centered at $50 / 60 \mathrm{~Hz}$ ) is a major problem during the recording of the ECG signals. Therefore, suppression of the PLI components from the ECG signals is required. This suppression can be executed via different types of notch filters $[2,3]$.

On the other hand, advances in technology lead to increase the demand for low power consumption and lower dimensional devices. Low power applications are provided at lower dimensional devices. By this way, decreasing channel length gives rise to the leakage current problems. In order to minimize leakage currents, threshold voltage cannot be held below a certain limit in regular MOSFETs [4, 5]. As a result, dynamic threshold voltage MOSFET (DTMOS) structure offers an opportunity for ultra low voltage applications [6, 7].

Floating Current Source structure has been firstly proposed as output stage of current-mode feedback amplifier (CFA) [8]. Some benefits of this structure are as follows; succession of output currents for any input, unaffected by transistor matching, low total harmonic distortion [8]. All of these benefits show that FCS isn't only an output stage for CFA but also takes place in various studies such as non-feedback differential amplifier, full-wave rectifier, negative second generation current conveyor, and filter operation [9-12].

In this study, p-MOSFETs in FCS circuit are converted to DTMOS. In addition, a second order notch filter is constructed using the DTMOS-FCS circuit, and the proposed filter circuit can be used to suppress the PLI components from the ECG signals.

\section{DTMOS Structure}

Regular MOSFETs are converted to DTMOS by connecting the bulk and gate in standard CMOS manufacturing process $[6,7]$. DTMOS structure and its circuit symbol are shown in Figure 1. As mentioned in previous section, DTMOS structure allows ultra low power applications. This is achieved by applying forward bias to body-source junction in order to reduce threshold voltage $\left(\mathrm{V}_{\mathrm{TH}}\right)$ of DTMOS (Equation-1) [6, 7]. By reduction of threshold voltage, inversion charge $\left(\mathrm{Q}_{\mathrm{N}}\right)$ is increased 
(Equation-2). So, larger inversion charge leads to a higher current drive in DTMOS in comparison to the regular MOSFETs [6, 7].

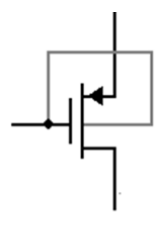

(a)

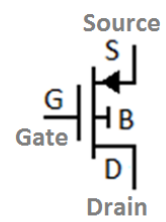

(b)
Figure 1. (a) The structure of DTMOS and (b) its circuit symbol [5].

$V_{T H}=2 \Phi_{B}+V_{F B}+\gamma \sqrt{2 \Phi_{B}-V_{B S}}$

where $\gamma$ is the body effect parameter. $V_{F B}$ and $V_{B S}$ represent the flat band voltage and bulk to source voltage, respectively. $\Phi_{\mathrm{B}}$ is inversion layer potential.

$\mathrm{dQ}_{\mathrm{n}}=\mathrm{C}_{\mathrm{OX}}\left(\mathrm{dV}_{\mathrm{G}}-\frac{\mathrm{dV}_{\mathrm{TH}}}{\mathrm{dV}_{\mathrm{G}}} \mathrm{dV_{ \textrm {G } }}\right)$

where $C_{O X}$ is the oxide capacitance and $V_{G}$ is the gate voltage.

\section{DTMOS based FCS Circuit}

FCS circuit possesses two input and two output stages as shown in Figure 2. And the circuit includes two PMOS and two NMOS devices. The most important feature of this structure is to following of the output currents each other with a phase angle difference of 180 degrees [8]. By using Kirchoff Current Law, it can be seen that output currents follow each other:

$$
\begin{aligned}
& \mathrm{I}_{\mathrm{B} 1}-\mathrm{I}_{\mathrm{B} 2}-\left(\mathrm{I}_{\text {OutN }}+\mathrm{I}_{\text {OutP }}\right)=0 \\
& \mathrm{I}_{\mathrm{B} 1}=\mathrm{I}_{\mathrm{B} 2}=\mathrm{I} \\
& \mathrm{I}_{\text {OutN }}=-\mathrm{I}_{\text {OutP }}
\end{aligned}
$$

where $\mathrm{I}_{\mathrm{B} 1}$ and $\mathrm{I}_{\mathrm{B} 2}$ represent bias currents.

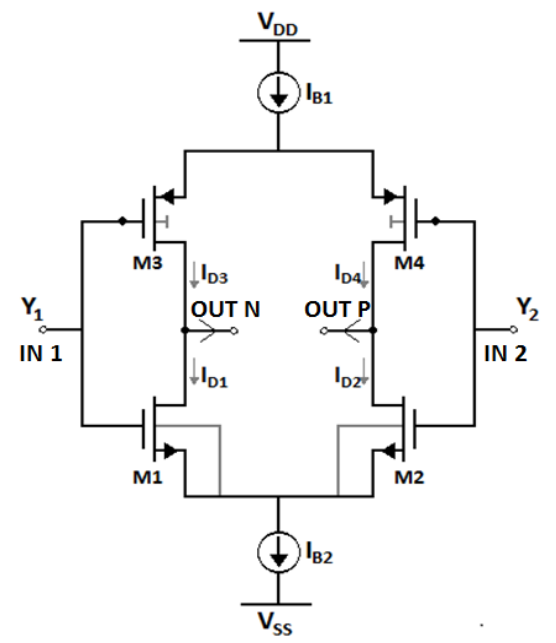

Figure 2. The circuit of DTMOS based FCS.

\section{Second Order Notch Filter}

In order to suppress the PLI components from the ECG signals, the notch filter [13] seen in Figure 3 is utilized. The notch filter is constructed using DTMOS based FCS circuit. Transfer function $(\mathrm{H})$ and quality factor $(\mathrm{Q})$ equations of the notch filter are as follows [13]:

$\mathrm{H}_{\text {bandstop }}(\mathrm{s})=\frac{\mathrm{s}^{2} \mathrm{C}_{1} \mathrm{C}_{2}+\mathrm{g}_{\mathrm{m} 1} \mathrm{~g}_{\mathrm{m} 2}}{\mathrm{~s}^{2} \mathrm{C}_{1} \mathrm{C}_{2}+\mathrm{sC}_{1} \mathrm{~g}_{\mathrm{m} 2}+\mathrm{g}_{\mathrm{m} 1} \mathrm{gm}_{\mathrm{m} 2}}$

$\mathrm{Q}=\frac{\sqrt{\mathrm{C}_{2} \mathrm{~g}_{\mathrm{m} 1}}}{\sqrt{\mathrm{C}_{1} \mathrm{~g}_{2}}}$

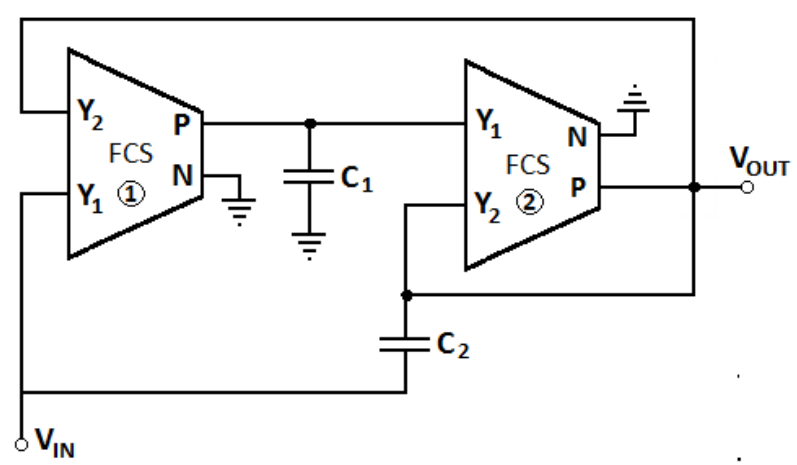

Figure 3. DTMOS-FCS based second order notch filter [13].

\section{Second Order Notch Filter}

The proposed model is simulated in LTSPICE simulator by using TSMC $0,18 \mu \mathrm{m}$ CMOS technology. Voltage sources, bias currents, and input voltage are chosen as given in Table 1 and aspect ratios of the transistors are given in Table 2.

Table 1. DTMOS-FCS Circuit Parameters.

\begin{tabular}{|l|c|}
\hline \multicolumn{1}{|c|}{ Parameters } & \multicolumn{1}{c|}{ Values } \\
\hline Voltage Sources & $\mathrm{V}_{\mathrm{DD}}=-\mathrm{V}_{\mathrm{SS}}=0,15 \mathrm{~V}$ \\
\hline Bias Currents & $\mathrm{I}_{\mathrm{B} 1}=\mathrm{I}_{\mathrm{B} 2}=16,5 \mathrm{nA}$ \\
\hline Input Voltage $(\mathrm{AC})$ & $\mathrm{V}_{\mathrm{IN}}=0,03 \mathrm{~V}_{\mathrm{AC}}(1 \mathrm{kHz})$ \\
\hline
\end{tabular}

Table 2. Aspect Ratios of MOSFETs.

\begin{tabular}{|c|c|}
\hline MOSFETs & Aspect Ratios (W/L) \\
\hline M1 - M2 & $300 \mu \mathrm{m} / 2 \mu \mathrm{m}$ \\
\hline M3 - M4 & $5 \mu \mathrm{m} / 2 \mu \mathrm{m}$ \\
\hline
\end{tabular}

Simulation results of the proposed model are shown in Figure 4 - 7. DC analysis and AC analysis of DTMOS-FCS circuit can be seen in Figure 4 and Figure 5. Output currents follow each other with phase angle difference of $180^{\circ}$ as expected from the characteristic equation. For $\mathrm{AC}$ analysis, power consumption is calculated as $4,95 \mathrm{nW}$. In addition, transconductance is observed as $231,289 \mathrm{n} \Omega^{-1}$ (Figure 6) and it can be said from Figure 6 that the filter circuit can be used for approximately $20 \mathrm{kHz}$ bandwidth. 


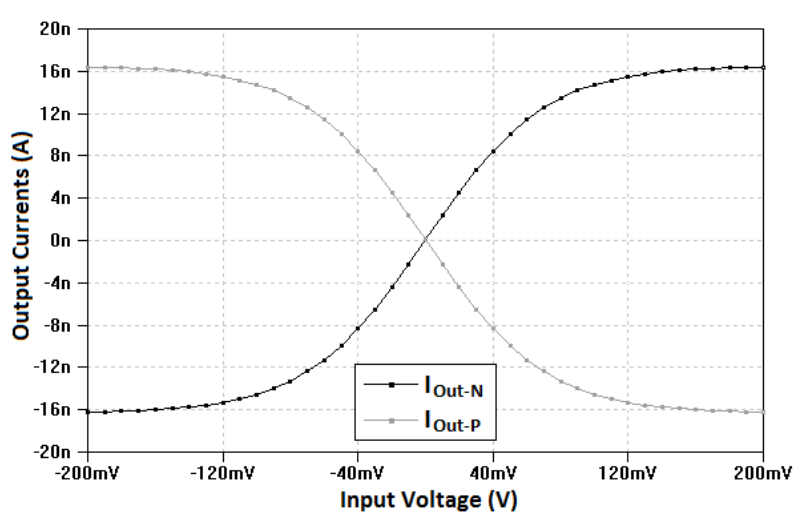

Figure 4. The DC transfer characteristics of DTMOSFCS circuit.

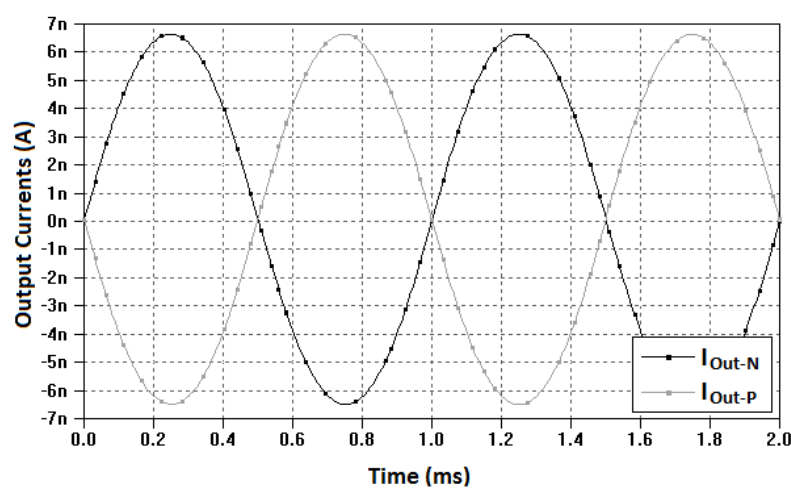

Figure 5. The output currents of DTMOS-FCS circuit.

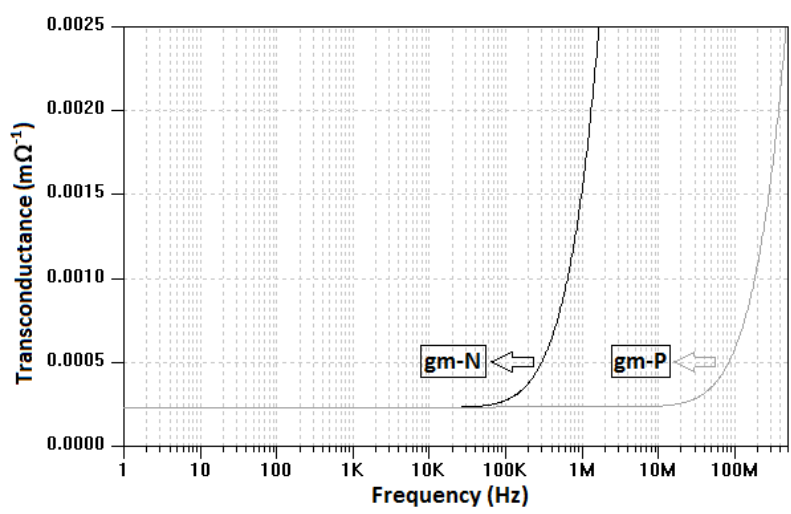

Figure 6. The transconductance of DTMOS-FCS circuit.

\subsection{Notch Filter Application of DTMOS-FCS Circuit}

The proposed notch filter is operated by using simulator and the frequency response of the filter is given in Figure 7. Capacitor values of the proposed filter are adjusted to reach the interference frequency. Capacitor values are chosen as; $\mathrm{C}_{1}=$ $210 \mathrm{pF}$ and $\mathrm{C}_{2}=2100 \mathrm{pF}$. By means of Equation 7, Q parameter of notch-filter is calculated as 3. Total harmonic distortion is obtained about $0,12 \%$. Operating frequency of the filter is about $55 \mathrm{~Hz}$ that is located at frequency range of PLI. Thus, it can be said that this structure can be used to suppress PLI components.
Moreover, it can be inferred from Figure 7 that DTMOS structure also allows to operate at lower frequencies. In the FCS circuit, that doesn't include DTMOS, it will be required higher value capacitances to reach the interference frequency.

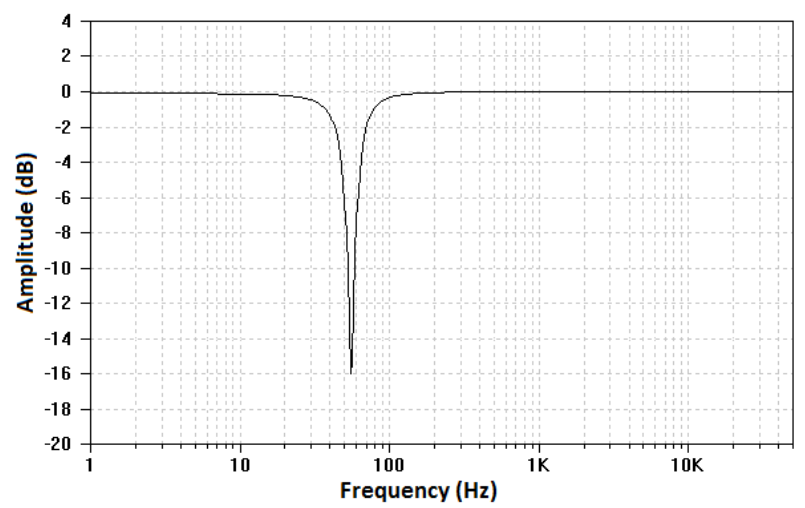

Figure 7. The response of DTMOS-FCS notch filter.

\section{Conclusions}

In the conclusion, DTMOS based FCS circuit has low power consumption as $4,95 \mathrm{nW}$ and its second order notch filter application is suitable to suppress the power line interference which is a major problem for the ECG signals. It can be said that DTMOS based FCS structure is favourable in terms of lower power consumption and dimension considerations in integrated circuits.

\section{References}

[1] W. Philips, "Adaptive Noise Removal from Biomedical Signals using Warped Polynomials", IEEE TRANSACTIONS ON BIOMEDICAL ENGINEERING, VOL 43, NO. 5 (1996), Pages 480492. DOI: $10.1109 / 10.488796$

[2] Chavdar Levkov, Georgy Mihov, Ratcho Ivanov, Ivan Daskalov, Ivaylo Christov and Ivan Dotsinsky, 2005, "Removal of power-line interference from the ECG: a review of the subtraction procedure", BioMedical Engineering OnLine 2005, 4:50. DOI: 10.1186/1475-925X-4-50

[3] Uzzal Biswas, Md. Maniruzzaman, 10-12 April 2014, "Removing Power Line Interference from ECG Signal using Adaptive Filter and Notch Filter", ICEEICT - International Conference on Electrical Engineering and Information Communication Technology. DOI: 10.1109/ICEEICT.2014.6919072

[4] D. Liu and C. Svensson, "Trading speed for lowpower by choice of supply and threshold voltages," IEEE Journal of Solid-State Circuits, vol. 28, No:1, pp. 10-17, Jan. 1993. DOI: 10.1109/4.179198 
[5] Atilla UYGUR, Hakan KUNTMAN,2013, "DTMOS based 0.4V Ultra Low Voltage Low Power VDTA Design and Its Application to EEG Data Processing", Radioengineering Journal, VOL. 22, NO. 2, Pages: 458-466.

[6] Fariborz Assaderaghi, Stephen Parke, Dennis Sinitsky, Jeffrey Bokor, Ping $\mathrm{K}$. KO, Chenming $\mathrm{Hu}$, 1994, "A Dynamic Threshold Voltage MOSFET (DTMOS) for Very Low Voltage Operation", IEEE Electron Device Letters, Vol.15, No: 2, Pages: 510512. DOI: $10.1109 / 55.338420$

[7] Fariborz Assaderaghi, Dennis Sinitsky, Stephen A. Parke, Jeffrey Bokor, Ping K. Ko, Chenming Hu, 1997, "Dynamic Threshold-Voltage MOSFET (DTMOS) for Ultra-Low Voltage VLSI", IEEE TRANSACTIONS ON ELECTRON DEVICES, VOL. 44, NO. 3, Pages: 414-422. DOI: $10.1109 / 16.556151$

[8] Arie F. Arbel And Lavy Goldminz, 1992, "Output Stage for Current-Mode Feedback Amplifiers, Theory and Applications", Analog Integrated Circuits and Signal Processing, Vol:2, No:3, Pages:243-255. DOI: $10.1007 / \mathrm{BF} 00276637$

[9] Lavy Goldminz and Arie Arbel, 1992, "Feasibility study of current mode differential amplifier design", IEEE International Symposium on Circuits and Systems ISCAS' 92 Proceedings, Pages 2856-2859. DOI: 10.1109/ISCAS.1992.230604

[10] Muhammed Emin Başak, Furat Kaçar, 2015, "A New Fully Integrated High Frequency Full- Wave Rectifier Realization", Journal of Microelectronics, Electronic Components and Materials Vol. 45, No. 2, Pages 101-109.

[11] Mostafa H., and Soliman A. M., "Novel Low-Power Accurate Wide-band CMOS Negative Second Generation Current Conveyor Realizations Based on Floating Current Source Building Blocks", Science and Technology for Humanity (TIC-STH), IEEE Toronto International Conference, 26-27 Sept. 2009, pp. 720-725. DOI: 10.1109/TIC-STH.2009.5444406

[12]Fırat Kaçar, Arsen A.M. Shakir, Yasin Özçelep, 2014, "A 4th Order Differential Gm-C Band-Pass Filter Using Improved Floating Current Source", Journal of Microelectronics, Electronic Components and Materials Vol. 44, No. 2, Pages 137-141.

[13] Rajeshwari S. Mathad, M. M. Mutsaddi, Girija M. Nimbal, Manjula V. Katageri, S. V. Halse, 2014, "Design of OTA-C Notch Filter in Mega Hertz frequency range", International Journal of Engineering Research and Development, Volume 10, Issue 3, Pages: 48-54. 